\title{
Mffedias \\ EFEKTIVITAS SUSPENSI EKSTRAK ETANOL UMBI BAWANG PUTIH (Allium sativum L.) SEBAGAI DIURETIK PADA TIKUS PUTIH JANTAN (Rattus norvegicus)
}

\section{EFFICACY OF GARLIC TUBER EXTRACT (Allium sativum L.) AS A DIURETIC IN MALE WHITE RATS (Rattus norvegicus)}

\author{
Selvi Marcellia*, Dewi Chusniasih, Aprilia Andansari
}

Program Studi Farmasi, Fakultas Kedokteran, Universitas Malahayati

*Koresponden Email : selvicellia@gmail.com

DOI: https://doi.org/10.32382/mf.v16i2.1693

\begin{abstract}
Garlic (Allium sativum L.) contains phallovonoids and alkaloids, which have a mild effect on urine. However, it has not been scientifically proven. This research aims to determine the effectiveness of garlic ethanol extract (Allium sativum L.) as a diuretic in Sprague dawley male white rats and to determine the optimum dose of garlic ethanol extract $96 \%$ as a diuretic. This experiment was carried out on 20 rats divided into five groups, each group consists of 4 rats. Groups I, II, III received garlic extract with a concentration of $25 \mathrm{mg} / \mathrm{KgBW} ; 35 \mathrm{mg} / \mathrm{KgBW}$ and $45 \mathrm{mg} / \mathrm{KgBW}$, while group IV received $0.5 \% \mathrm{Na}$.CMC as a negative control and group $\mathrm{V}$ as a positive control received furosemide at a dose of $20 \mathrm{mg} / \mathrm{kgBW}$. Based on the results, each treatment group I, II, III, IV, and V obtained an average urine volume value of $2.95 \mathrm{ml}, 3.27$ $\mathrm{ml}, 3.76 \mathrm{ml}, 2.3 \mathrm{ml}, 4.57 \mathrm{ml}$. Therefore, it was concluded that all the treatment groups using garlic extract suspension were able to increase urine volume more than the control, in which the optimal dose of garlic extract suspension was $45 \mathrm{mg} / \mathrm{kgBW}$, but the effect was smaller compared to furosemide ( $\mathrm{p}<0.05$ ).
\end{abstract}

Keywords : Garlic Extract, Allium sativum, Diuretic, Suspension, Ethanol

\section{ABSTRAK}

Bawang putih (Allium sativum L.) memiliki kandungan falovonoid dan alkaloid, yang diduga mampu memberikan efek pelancar kemih, namun hal ini masih perlu dibuktikan secara ilmiah. Penelitian ini bertujuan untuk mengetahui efektivitas ekstrak etanol bawang putih (Allium sativum L.) sebagai diuretik pada hewan tikus putih jantan galur Sprague dawley dan untuk mengetahui dosis optimum ekstrak etanol $96 \%$ bawang putih yang berkhasiat sebagai diuretik. Percobaan ini dilakukan terhadap 20 ekor tikus yang dibagi menjadi lima kelompok tiap kelompok terdiri dari 4 ekor tikus. Kelompok I, II, III diberikan ekstrak bawang putih dengan konsentrasi $25 \mathrm{mg} / \mathrm{KgBB} ; 35 \mathrm{mg} / \mathrm{KgBB}$ dan $45 \mathrm{mg} / \mathrm{KgBB}$, sedangkan kelompok IV sebagai kontrol negatif diberikan Na.CMC 0,5\% dan kelompok $\mathrm{V}$ sebagai kontrol positif diberikan furosemid dengan dosis $20 \mathrm{mg} / \mathrm{kgBB}$. Dari hasil penelitian masing-masing kelompok perlakuan I, II, III, IV, dan V didapat nilai rata-rata volume urin yaitu 2,95 ml, 3,27 ml, 3,76 ml, 2,3 ml, 4,57 ml. Sehingga dapat disimpulkan semua kelompok perlakuan yang menggunakan suspensi ekstrak bawang putih mampu meningkatkan volume urin lebih besar dari kontrol dimana dosis optimal suspensi ekstrak bawang putih adalah $45 \mathrm{mg} / \mathrm{kgBB}$ namun efeknya masih lebih kecil jika dibandingkan dengan furosemid $(\mathrm{p}<0,05)$

\section{Kata kunci : Ekstrak Bawang Putih, Allium sativum, Diuretik, Suspensi, Etanol}

\section{PENDAHULUAN}

Dewasa ini minat masyarakat untuk kembali pada pengobatan tradisional semakin meningkat. Pengobatan dengan ramuan tradisional dirasakan lebih murah dari pada obat kimiawi sintetik. Peluang untuk mendapatkan ramuan mujarab dan mudah diperoleh masih terbuka lebar, mengingat potensi tanaman obat Indonesia yang tinggi dan belum termanfaatkan semuanya. Salah satu kegunaan obat tradisional adalah sebagai diuretik (Saifudin, 2011).

Diuretik merupakan suatu golongan obat yang dapat meningkatkan laju produksi volume urin sehingga garam-garam di dalam tubuh dapat keluar bersama urin, jika garamgaram di dalam tubuh dapat keluar bersama urine maka akan meningkatkan pengeluaran air dan menyebabkan volume urine bertambah, dengan berkurangnya air maka tekanan darah akan 
menurun. Diuretika digunakan pada semua keadaan dimana dikehendaki peningkatan pengeluaran air, khususnya pada hipertensi, gagal jantung, penyakit ginjal kronik, diabetes (Tjay \& Rahardja, 2002 dalam Mulyaningsih, $\underline{\text { 2016) }}$

Salah satu tanaman yang berkhasiat sebagai obat alternatif diuretik adalah bawang putih karena diketahui bawang putih memiliki kandungan falovonoid dan alkaloid. Bawang putih mengandung setidaknya 33 komponen sulfur, 17 asam amino, dan banyak mineral seperti selenium. Dalam hal kesehatan bawang putih memiliki berbagai khasiat salah satu khasiatnya adalah memiliki efek pelancar kemih atau disebut juga diuretik (Salima, 2015).

Bawang putih banyak mengandung minyak menguap (volatile oil) berupa senyawa sulfur (seperti allicin, allisatin, allinase, allylpropyl disulphide, diallyl trisulphide /DATS), glucosinolate, enzim, vitamin. Selain itu terdapat kandungan flavonoid dan alkaloid pada bawang putih, dimana kandungan tersebut berkhasiat sebagai diuretik (Wardani \& Adrianta, 2016; Isnania et al., 2014).

Berdasarkan Penelitian yang dilakukan oleh Lestari et al., (2016) menyatakan hasil penapisan fitokimia menunjukkan bahwa bawang bombay mengandung alkaloid, flavonoid, glikosida, saponin sulfur dan allisin, dimana allisin merupakan senyawa golongan sulfur yang dapat menurunkan tekanan darah namun senyawa aktif dalam bawang bombay yang berkhasiat sebagai diuretik adalah flavonoid dan alkaloid. Dosis optimal umbi bawang bombay sebagai diuretik adalah 80 $\mathrm{mg} / \mathrm{KgBB}$ yang hampir setara dengan furosemid $0,36 \mathrm{mg} / 200 \mathrm{~g} \mathrm{BB}$ pada tikus putih jantan galur Sprague dawley.

Menurut penelitian yang dilakukan Tiwari et al (2012), menyatakan bahwa ekstrak n-butanol dari Allium sativum dengan dosis $10 \mathrm{mg} / \mathrm{kg}$ tidak signifikan tetapi pada dosis $20 \mathrm{mg} / \mathrm{kg}$ signifikan menyebabkan peningkatan volume urin. Studi ini menyimpulkan bahwa Allium sativum memiliki aktivitas diuretik, sehingga memvalidasi tanaman tradisional ini sebagai diuretik.

Berdasarkan penjelasan dari latar belakang yang ada mengenai ekstrak bawang putih (Allium sativum L) sebagai diuretik peneliti tertarik ingin meneliti kemampuan diuretik pada ekstrak etanol $96 \%$ pada bawang putih yang sifat toksik pelarutnya di bawah pelarut n-butanol. Sehingga penelitian ini bertujuan untuk mengetahui efektivitas ekstrak etanol bawang putih (Allium sativum L.) sebagai diuretik pada hewan tikus putih jantan galur Sprague dawley dan untuk mengetahui dosis optimum ekstrak etanol $96 \%$ bawang putih yang berkhasiat sebagai diuretik.

\section{METODE}

Penelitian ini dilakukan pada bulan Agustus - September 2019 yang dilaksanakan di laboratorium Biologi II FMIPA Unila, Balai Veteriner, dan Laboratorium Farmakologi Universitas Malahayati.

Alat yang akan digunakan pada penelitian ini adalah batang pengaduk, botol gelap, corong, erlenmeyer $500 \mathrm{ml}$, gelas ukur 100 $\mathrm{ml}$, kertas saring, kandang metabolisme, penangas air, labu ukur $100 \mathrm{ml}$, mortir dan stamper, spuit 1cc, Rotary Evaporator, timbangan analitik, beaker glass $200 \mathrm{ml}$, stopwatch, hand glove, toples.

Bahan yang akan digunakan pada penelitian ini adalah simplisia Umbi Bawang Putih, Furosemid tablet 40 mg, CMC Na, Larutan Pereaksi Bouchardat, larutan pereaksi mayer, larutan pereaksi dragendorf, HCL 2N, etil asetat, Aquadest, Etanol 96\%, serbuk seng P, asam asetat anhidrat, HCL P, Tikus putih jantan.

\section{Prosedur Penelitian \\ Determinasi Umbi Bawang Putih}

Determinasi Umbi bawang putih (Allium sativum, L.) dilakukan di Laboratorium Biologi FMIPA Unviersitas Lampung.

\section{Pembuatan Ekstrak}

Dari umbi bawang putih (Allium sativum, L.) yang diambil sebanyak $3 \mathrm{~kg}$. Bawang putih yang digunakan dibersihkan dari kulitnya, kemudian dicuci bersih dengan air mengalir dan ditiriskan, Umbi bawang putih lalu dikeringkan dengan cara diangin-anginkan kurang lebih selama 3 hari sampai bawang putih benar-benar kering tidak ada kandungan airnya lagi, kemudian di blender menjadi simplisia. Pembuatan ekstrak Umbi bawang putih dilakukan dengan cara maserasi menggunakan pelarut etanol 96\% sebanyak 4,5 liter. Maserasi dilakukan selama 3 hari dengan merendam 500 gram simplisia Umbi bawang putih dengan 1,5 liter etanol $96 \%$ sampai terendam, lalu beaker ditutup dan dilapisi dengan alumunium foil. Setelah perendaman selama 3 hari, kemudian disaring menggunakan kertas saring. Digabungkan filtrat yang didapat dan dipekatkan dengan menggunakan rotary evaporator sampai diperoleh ekstrak kental selanjutnya dilakukan pengovenan sampai diperoleh ekstrak dalam bentuk pasta (Ditjen POM, 1995). 


\section{Uji Penapisan Fitokimia \\ Identifikasi Alkaloid}

Ekstrak 0,5 gram ditambahkan $1 \mathrm{~mL}$ asam klorida $2 \mathrm{~N}$ kemudian $9 \mathrm{ml}$ aquadest, dipanaskan pada penangas air selama 2 menit. Setelah dingin, campuran disaring dan filtrat ditambahkan beberapa tetes reagen Bouchardart LP, terbentuk endapan coklat sampai dengan hitam (positif alkaloid) (Depkes RI, 1995 ; Farnswort, 1966).

\section{Identifikasi Flavonoid}

Ekstrak 0,5 gram dalam cawan ditambahkan $2 \mathrm{~mL}$ etanol $70 \%$ kemudian diaduk, ditambahkan serbuk magnesium 0,5 g dan 3 tetes $\mathrm{HCl}$ pekat. Terbentuknya warna jingga sampai merah (positif flavonoid) (Mojab, 2003).

\section{Identifikasi Saponin}

Ekstrak 0,5 gram dalam tabung reaksi ditambahkan $2 \mathrm{~mL}$ etanol 70\% kemudian diaduk, ditambahkan dengan $20 \mathrm{~mL}$ aquades dan dikocok kemudian didiamkan selama 15-20 menit. Jika tidak ada buih = negatif; buih lebih dari $1 \mathrm{~cm}=$ positif lemah; busa dengan tinggi $1,2 \mathrm{~cm}=$ positif; dan buih lebih besar dari $2 \mathrm{~cm}=$ positif kuat (Mojab, 2003).

\section{Identifikasi Tanin}

Ekstrak 0,5 gram dalam cawan ditambahkan 2 mL etanol $70 \%$ kemudian diaduk, ditambahkan $\mathrm{FeCl} 3$ sebanyak 3 tetes, jika menghasilkan biru karakteristik, biru-hitam, hijau atau biru-hijau dan endapan (Mojab, 2003).

\section{Identifikasi Sulfur}

Ekstrak 0,5 gram diasamkan dengan asam asetat dan larutan timbal asetat, di ambil ekstrak dalam tabung reaksi tambahkan 2-3 tetes Natrium Nitrogen Prusside maka akan terbentuk warna ungu yang tak tetap (Whitten,et.al, 2009).

\section{Identifikasi Triterpenoid dan Steroid}

Ekstrak sebanyak 0,5 gram dimasukkan dalam tabung reaksi. Ditambahkan $2 \mathrm{ml}$ etil asetat dan dikocok. lapisan etil asetat diambil lalu ditetesi pada plat tetes dibiarkan sampai kering. Setelah kering ditambahkan 2 tetes asam asetat anhidrat dan 1 tetes asam sulfat pekat. Apabila terbentuk warna merah atau kuning berarti positif terpenoid. Apabila terbentuk warna hijau berarti positif steroid.

\section{Persiapan Hewan Uji}

Hewan Uji yang digunakan dalam penelitian ini adalah Tikus Putih Jantan (Rattus norvegicus) galur Sprague Dawley yang berumur 2-3 bulan dengan bobot \pm 200 gram sebanyak 20 ekor. Persiapan tikus dilakukan dengan cara :

a. Semua tikus dibagi dalam 5 kelompok perlakuan, setiap kelompok terdiri dari 4 ekor tikus yang berada pada 1 kandang dan diadaptasi selama 14 hari.

b. Setelah 14 hari adaptasi, sebelum dilakukan perlakuan tikus terlebih dahulu dipuasakan selama 18 jam tanpa diberi makan agar tidak mempengaruhi efek dari ekstrak umbi bawang putih tetapi selama puasa 18 jam tikus tetap diberi minum dengan tujuan agar kondisi elektrolit tikus tetap stabil. Sebelum pengujian, tikus diberikan berupa aquadest hangat sebanyak $50 \mathrm{ml} / \mathrm{kgBB}$ baru kemudian dicekokan masing-masing perlakuan dengan dosis pemberian $1 \mathrm{ml} / 100$ gramBB.

\section{Penetapan Dosis}

Dalam penetepan dosis yang digunakan pada penelitian ini adalah sebagai berikut:

a. Dosis Ekstrak Bawang Putih

Dosis ekstrak bawang putih $25 \mathrm{mg}, 35 \mathrm{mg}$ dan $45 \mathrm{mg} / \mathrm{kgBB}$.

b. Dosis Furosemid

Dosis minimum perhari furosemid yang diberikan untuk manusia $(70 \mathrm{~kg})$ yaitu $20 \mathrm{mg} / \mathrm{kgBB}$ maka dosis untuk tikus (200 gram) adalah 200 gram tikus:

$20 \mathrm{mg} / \mathrm{kgBB} \times 70 \mathrm{kgBB} \quad \mathrm{x} \quad 0,018=25,2$ $\mathrm{mg} / 200$ gramBB $\rightarrow 200 / 1000=0,2 \mathrm{KgBB}=$ $25,2 \mathrm{mg} / 0,2 \mathrm{kgBB}=126 \mathrm{mg} / \mathrm{kgBB}$.

\section{Pembuatan Sediaan Suspensi}

Pembuatan larutan Na. CMC menggunakan kadar yang dianjurkan, yaitu $0,5 \%$ b/v. Timbang 0,5 gram Na. CMC, kemudiaan taburkan di atas air panas $100 \mathrm{ml}$, aduk kuat-kuat dalam lumpang sampai homogen, hingga didapatkan konsentrasi suspensi Na. CMC 0,5\% $\mathrm{b} / \mathrm{v}$.

\section{Pemberian Ekstrak Bawang Putih}

Pada percobaan ini 20 ekor tikus dibagi secara acak menjadi lima kelompok, masingmasing 4 ekor dengan perincian sebagai berikut: Kelompok 1 : Diberikan ekstrak bawang putih dengan dosis $25 \mathrm{mg} / \mathrm{kgBB}$.

Kelompok 2 : Diberikan ekstrak bawang putih dengan dosis $35 \mathrm{mg} / \mathrm{kgBB}$.

Kelompok 3 : Diberikan ekstrak bawang putih dengan dosis $45 \mathrm{mg} / \mathrm{kgBB}$.

Kelompok 4 : Kontrol normal, kelompok tanpa diberikan perlakuan, hanya diberikan $\mathrm{Na}$ CMC 0,5\% secara oral.

Kelompok 5 : Kontrol positif, kelompok yang diberikan pembanding furosemid dengan dosis $126 \mathrm{mg} / \mathrm{kgBB}$.

Pemberian ekstrak dilakukan secara oral dengan bantuan sonde sesuai dosis yang ditentukan. 


\section{Pengukuran Volume Urin}

Untuk melakukan pengukuran volum urin, tikus ditempatkan dalam kandang metabolit yang sebelumnya diletakkan wadah penampung urin. Selanjutnya, pengamatan dilakukan terhadap volume urin yang dikeluarkan pada jam ke-1, 2, 3, 4, 5, 6. Urin yang akan diukur volumenya diambil menggunakan gelas ukur.

\section{HASIL}

Hasil uji fitokimia terhadap ekstrak umbi bawang putih dapat dilihat pada Tabel 1.

Tabel 1. Hasil Pengamatan Uji Fitokimia

\begin{tabular}{llcc}
\hline No & Uji Penapisan & Indikator uji & Keterangan \\
\hline 1 & Alkaloid & Endapan coklat & + \\
2 & Flavonoid & Merah jingga & + \\
3 & Saponin & Terbentuk buih & + \\
4 & Tanin & - & - \\
5 & Sulfur & Warna ungu & + \\
6 & Triterpenoid & Kuning & + \\
7 & Steroid & - & - \\
\hline
\end{tabular}

Keterangan $:(+)=$ Ada $(-)=$ Tidak Ada

Hasil uji fitokimia pada Tabel 1 didapatkan hasil positif pada alkaloid, flavonoid, saponin, sulfur, triterpenoid, dan negatif pada Tanin dan Steroid. Dari lima senyawa metabolit sekunder yang terkandung dalam ekstrak bawang putih diketahui memiliki sifat sebagai antidiuretik.

Hasil yang didapat dalam uji efektivitas Ekstrak Umbi Bawang Putih sebagai antidiuretik dapat dilihat pada Tabel 2.

Tabel 2. Hasil Uji Efektivitas Ekstrak Umbi Bawang Putih dan Uji ANOVA

\begin{tabular}{|c|c|c|c|c|c|c|c|c|c|c|c|c|c|}
\hline \multirow{2}{*}{$\begin{array}{c}\text { Uji } \\
\text { Diure } \\
\text { tik }\end{array}$} & \multicolumn{13}{|c|}{ Volume urin rata-rata perjam $(\mathrm{ml})$} \\
\hline & $\begin{array}{l}\text { Jam } \\
\text { ke-1 }\end{array}$ & $\begin{array}{c}\text { p- } \\
\text { value }\end{array}$ & $\begin{array}{l}\text { Jam } \\
\text { ke-2 }\end{array}$ & $\begin{array}{c}\text { p- } \\
\text { value }\end{array}$ & $\begin{array}{l}\text { Jam } \\
\text { ke-3 }\end{array}$ & $\begin{array}{c}\text { p- } \\
\text { value }\end{array}$ & $\begin{array}{l}\text { Jam } \\
\text { ke-4 }\end{array}$ & $\begin{array}{c}\text { p- } \\
\text { value }\end{array}$ & $\begin{array}{l}\text { Jam } \\
\text { ke-5 }\end{array}$ & $\begin{array}{c}\text { p- } \\
\text { value }\end{array}$ & $\begin{array}{l}\text { Jam } \\
\text { ke-6 }\end{array}$ & $\begin{array}{c}\text { p- } \\
\text { value }\end{array}$ & $\begin{array}{c}\text { Total } \\
(\mathrm{ml})\end{array}$ \\
\hline F1 & 0,275 & \multirow{5}{*}{0,087} & 0,8 & \multirow{5}{*}{0,018} & 0,95 & \multirow{5}{*}{0,002} & 0,65 & \multirow{5}{*}{0,000} & 0,5 & \multirow{5}{*}{0,004} & 0,125 & \multirow{5}{*}{0,001} & 2,95 \\
\hline $\mathrm{F} 2$ & 0,275 & & 0,325 & & 1,40 & & 0,575 & & 0,462 & & 0,237 & & 3,27 \\
\hline F3 & 1,0 & & 0,625 & & 1,425 & & 0,287 & & 0,275 & & 0,137 & & 3,76 \\
\hline $\mathrm{F} 4$ & 0,2 & & 0,362 & & 0,837 & & 0,575 & & 0,2 & & 0,125 & & 2,3 \\
\hline F5 & 1,325 & & 0,55 & & 1,337 & & 0,637 & & 0,4 & & 0,325 & & 4,57 \\
\hline
\end{tabular}

Keterangan :

F1 : Kelompok 1 (Dosis ekstrak 25mg/kgB)

F2 : Kelompok 2 (Dosis ekstrak 35mg/kgBB)

F3 : Kelompok 3 (Dosis ekstrak 45mg/kgBB)

F4 : Kelompok 4 (Kontrol Normal Na.CMC)

F5 : Kelompok 5 (Kontrol Positif Furosemid)

\section{PEMBAHASAN}

Dapat dilihat bahwa rata-rata volume urin tiap kelompok selama 6 jam pada Kelompok 1, Kelompok 2, Kelompok 3, mengalami peningkatan volume urin. Kenaikan volume urin tersebut disebabkan karena adanya kandungan alkaloid, flavonoid, saponin yang bekerja sinergis dalam meningkatkan volume urin (diuresis). Alkaloid dapat memberikan efek diuretik dengan cara bekerja langsung pada tubulus dengan cara meningkatkan ekskresi $\mathrm{Na}^{+}$ dan $\mathrm{Cl}^{-}$. Dengan meningkatnya ekskresi $\mathrm{Na}^{+}$juga akan meningkatkan ekskresi air dan menyebabkan volume urin bertambah. Sementara itu, Flavonoid dapat meningkatkan volume urin dengan cara meningkatkan laju kecepatan glomerulus (Jouad, 2001). Selain itu flavonoid dapat menghambat reabsorbsi $\mathrm{Na}^{+}$dan $\mathrm{Cl}^{-}$sehingga menyebabkan peningkatan $\mathrm{Na}^{+}$dan air dalam tubulus kontortus proksimal dan tubulus kontortus distal. Dengan demikian, terjadi peningkatan volume air dalam tubulus dan terjadi peningkatan volume urin. Sedangkan Saponin merupakan senyawa hasil metabolisme sekunder pada beberapa tanaman bersifat menurunkan tegangan permukaan, merangsang ginjal untuk bekerja lebih aktif, dan meningkatkan absorbsi diuretik (Nalwaya N, et al., 2009). Apabila kelompok ekstrak F1, F2, dan F3 dibandingkan dengan kelompok kontrol 
normal (Na.CMC) terdapat perbedaan dimana volume urin rata-rata kelompok yang diberikan ekstrak lebih banyak menghasilkan urin yang menandakan ekstrak berefek sebagai diuretik. Kemudian dapat dilihat bahwa volume urin tertinggi terdapat pada jam ke-3 hal ini karena efek puncak diuretik yang diberikan secara oral terjadi setelah 2-3 jam, dan untuk kontrol positif (furosemid) jam ke-1 memang sudah mengalami kenaikan volume urin yang tinggi. Kenaikan volume urin yang tinggi sejak jam ke-1 tersebut dikarenakan furosemid sudah bekerja pada jam pertama, secara oral dalam 0,5-1 jam namun bertahan singkat pada 4-6 jam, secara intravena beberapa menit dan bertahan 2,5 jam lamanya (Tjay dan Rahardja, 2007).

Berdasarkan uji statistik, didapatkan data volume urin rata-rata perjam terdistribusi normal berdasarkan hasil uji Saphiro-wilk dengan nilai probabilitasnya yaitu 0,533 ( $>>0,05)$. hasil uji ANOVA didapatkan bahwa nilai signifikasi $(\mathrm{p}<0,05)$ adalah pada jam ke 2 , 3, 4, 5, dan 6. Hal ini berarti terdapat perbedaan bermakna $(\mathrm{p}<0,05)$ tiap-tiap jam antara kelompok uji, kecuali pada jam ke-1. P <0,05 terdapat perbedaan bermakna yang berarti data signifikan terdapat pada jam ke-2 nilai p yaitu 0,018 jam ke- 3 nilai p yaitu 0,002 , jam ke-4 nilai p yaitu 0,000 , jam ke-5 nilai p yaitu 0,004 , jam ke-6 nilai p yaitu 0,001 dan terdapat perbedaan tiap-tiap kelompok uji per-jamnya. Sedangkan nilai $\mathrm{p}>0,05$ yang berarti tidak signifikan yaitu terdapat pada jam ke-1 nilai p yaitu 0,087 , diduga pada saat jam ke-1 rata-rata volume urin masih rendah karena diuretik masih berefek kecil dalam tubuh tikus.Pemberian dosis ekstrak Kelompok 1, Kelompok 2, dan Kelompok 3 mengalami peningkatan volume urin, dan yang paling meningkatkan volume urin yaitu pada pemberian dosis ekstrak 3 (Dosis ekstrak 45mg/kgBB). Kenaikan volume urin tersebut disebabkan karena adanya kandungan alkaloid, flavonoid, saponin yang bekerja sinergis dalam meningkatkan volume urin (diuresis).

Pada penelitian sebelumnya yang dilakukan oleh (Tiwari et al., 2012) dengan perbandingan dosis ekstrak umbi bawang putih yakni $10 \mathrm{mg} / \mathrm{kgBB}$ dengan $20 \mathrm{mg} / \mathrm{kgBB}$ dengan pelarut $\mathrm{n}$-butanol didapatkan hasil dosis yang berefek sebagai diuretik yaitu dimulai dari $20 \mathrm{mg} / \mathrm{kgBB}$ sedangkan $10 \mathrm{mg} / \mathrm{kgBB}$ tidak memberikan efek. Sehingga pada penelitian kali ini dosis ditingkatkan menjadi $25 \mathrm{mg} / \mathrm{kgBB}$, $35 \mathrm{mg} / \mathrm{kgBB}$ dan $45 \mathrm{mg} / \mathrm{kgBB}$ dengan pelarut yang berbeda yaitu etanol $96 \%$ yang merupakan pelarut yang lebih umum digunakan dalam ekstraksi.
Dengan dosis 25mg/kgBB, $35 \mathrm{mg} / \mathrm{kgBB}$, dan $45 \mathrm{mg} / \mathrm{kgBB}$ maka didapatkan hasil yang signifikan dimana terdapat peningkatan volume urin tiap-tiap kelompok dan dosis yang paling berefek yaitu pada pemberian dosis ekstrak Kelompok 3 (Dosis ekstrak $45 \mathrm{mg} / \mathrm{kgBB})$. Dosis pada penelitian ini ditingkatkan karena pada penelitian sebelumnya dengan dosis $10 \mathrm{mg} / \mathrm{kgBB}$ tidak memiliki efek sedangkan dengan dosis $20 \mathrm{mg} / \mathrm{kgBB}$ memiliki efek yang sedikit, sehingga pada penelitian ini dosis ditingkatkan.

Hasil yang didapatkan pada penelitian sebelumnya oleh (Tiwari et al.,2012) memiliki efek diuretik yang sama jika dibandingkan dengan penelitian ini mengenai Efektivitas Suspensi Ekstrak Umbi Bawang Putih (Allium sativum L.) Sebagai Diuretik Pada Tikus Putih Jantan (Rattus norvegicus), yang membuktikan bahwa ekstrak umbi bawang putih sama-sama memiliki efek sebagai diuretik, dan hasil dari penelitian ini dosis paling tinggi $45 \mathrm{mg} / \mathrm{kgBB}$ yang memberikan efek diuretik yang tinggi. Pada penelitian sebelumnya terdapat perbedaan pada jumlah volume urin dimana volume urin pada penelitian ini lebih banyak, hal itu dikarenakan semakin tinggi dosis maka semakin tinggi efek diuretiknya. Pada penelitian ini hasil yang didapat pada kelompok perlakuan di bandingkan dengan kontrol positif (furosemid) masih lebih kecil, hal ini bisa disebakan oleh waktu pengambilan urin yang terlalu dekat sehingga volume urin yang dihasilkan kurang optimal. Semakin tinggi dosis ekstrak umbi bawang putih maka kandungan alkaloid, flavonoid dan saponin di dalam ekstrak umbi bawang putih semakin banyak, sehingga ketiga senyawa tersebut dapat bersinergis dalam merangsang kerja ginjal untuk memproduksi urin lebih banyak. Produksi urin yang lebih banyak dapat menjadi salah satu upaya terapi diuretik untuk mengatasi beberapa masalah kesehatan seperti edema paru, gagal jantung kronik, antidiabetik, ginjal kronik dan hipertensi.

Pada penelitian ini banyak terdapat kendala yang dihadapi oleh peneliti selama melaksanakan penelitian seperti proses aklimatisasi tikus yang rendah sehingga menyebabkan banyak tikus yang stress dan penurunan bobot tubuh tikus.

\section{KESIMPULAN}

Dari hasil penelitian efektivitas ekstrak umbi bawang putih (Allium sativum L.) sebagai diuretik pada tikus putih jantan dapat disimpulkan bahwa semua kelompok perlakuan yang menggunakan suspensi ekstrak bawang putih mampu meningkatkan volume urin lebih 
besar dari kontrol normal, namun jika dibandingkan dengan kontrol positif (furosemid) masih lebih kecil untuk volume urin yang dihasilkan. Dosis optimum ekstrak umbi bawang putih yang optimal sebagai diuretik adalah $45 \mathrm{mg} / \mathrm{kgBB}$ yang mendekati volume urin pada kontrol positif (furosemid).

SARAN

Dari hasil penelitian dan data, penulis dapat menyarankan untuk penelitian lebih lanjut mengenai Efektivitas Ekstrak Umbi bawang putih (Allium sativum L.) sebagai Diuretik pada Tikus Putih Jantan

\section{UCAPAN TERIMA KASIH}

Dalam proses pelaksanaan penelitian ini peneliti mengucapkan terima kasih kepada seluruh dosen pembimbing dan ketua Program Studi Farmasi yang telah banyak membantu dalam keberhasilan peneltian ini, dan juga Rektor Universitas Malalahayati serta Dekan Fakultas Kedokteran.

\section{DAFTAR PUSTAKA}

Ajayi, G. O., Adeniyi, T. T., \& Babayemi, D. O. 2009. Hepatoprotective and some haematological effects of Allium sativum and vitamin $\mathrm{C}$ in lead-exposed wistar rats. International Journal of Medicine and Medical Sciences, 1(3), 064-067.

Departemen Kesehatan. 2007. Kebijakan Obat Tradisional Nasional.: Departemen Kesehatan RI. Jakarta

Dharmeizar. 2012. Hipertensi. Medicinus: Scientific Journal of Pharmaceutical Development and Medical Application, Vol. 25, No. 1, hlm. 3-8

DiPiro J.T., Wells B.G., Schwinghammer T.L. and DiPiro C. V., 2015.Pharmacotherapy Handbook, Ninth Edit., McGraw-Hill Education

Companies, InggrisExeter, 1997. Monographs on the medicinal uses of plants. Exeter: European Scientific Cooperative on Phytotherapy.

Isnania, Fatmawati, dan Wehantouw, F. 2014. Aktivitas Diuretik Dan Skrining Fitokimia Ekstrak Etanol Biji Pepaya (Carica Papaya L.) Pada Tikus Putih Jantan Galur Wistar (Rattus Norvegicus). Jurnal Ilmiah Farmasi Vol. 3 No. 3.

Jouad, H., Lacaille-Dubois M. A., Lyoussi, B, Eddouks, M. 2001. Effects of the Flavonoids Extracted from Spergularia purperea Pers. On Arterial Blood Pressure and Renal Function in Normal and hypertensive Rats. Journal of Ethnopharmacology.

Kemenkes RI. 2013. Direk torat Jenderal PPM \& PLP; Pemberantasan Penyakit Menular dan Penyehatan Lingkungan. Jakarta.

Kemenkes RI. 2015. Rencana Strategis Kementerian Kesehatan Tahun 20152019. (Diakses melalui https://doi.org/351.077 Ind r).

Lestari, Y.P., Pratiwi, D., Setiawan, A.A. 2016. Uji Efektivitas Ekstrak Etanol 70\% Bawang Bombay (Allium cepa, L.) Sebagai Diuretik Pada Tikus Putih Jantan (Rattus norvegicus) Galur Sprague Dawley.

Mojab, F., Kamalinejad, M., Ghadeni, N., dan Vahidipour, H. R. (2003).Phytocemical Screening of Some Species of Iranian Plants. Iranian. Journal of Pharmaceutical Research

Mulyaningsih, W., 2016. Uji Efek Diuretik Ekstrak Etanol Daun Sukun Artocarpus Altilis (Parkinson) Fosberg terhadap Tikus Jantan Galur Wistar. (Doctoral dissertation). Fakultas MIPA: UNISBA.

Nalwaya, N., Jarald, E. E., Asghar, S., \& Ahmad, S. 2009. Diuretic activity of a herbal product UNEX. International Journal of Green Pharmacy (IJGP), 3(3).

Newall, C. A., Anderson, L. A., Phillipson, J. D. 1996. Herbal Medicines, A Guide for Health-care Professionals, London: The Pharmaceutical Press.

Pantoja, C. V., Chiang, L. C., Norris, B. C., Concha, J. B. 1991. Diuretic, natriuretic and hypotensive effects produced by Allium sativum (garlic) in anaesthetized dogs. Journal of Ethnopharmacology 31.

Rukmana, R. 1995. Budidaya Bawang Putih, Edisi ke-1. Yogyakarta: Kanisius.

Saifudin, A., Rahayu, \& Teruna, 2011. Standardisasi Bahan Obat Alam. Graha Ilmu : Yogyakarta.

Salima, J., 2015. Uji Daya Hambat dan Daya Bunuh Ekstrak Ethanol Bawang Putih (Allium sativum L.) terhadap Bakteri Staphylococcus aureus Secara IN VITRO. Antibacterial Activity of Garlic (Allium sativum L.), 4(2), pp.30-39.

Santoso, H. B. 2000. Bawang Putih, Edisi ke-12. Yogyakarta: Kanisius. 
Siswandono \& Soekardjo, B. 1995. Kimia Medisinal, Airlangga University Press, Surabaya.

Taringan, A.R., Lubis, Z., Syarifah. 2018. Pengaruh Pengetahuan, Sikap dan Dukungan Keluarga Terhadap Diet Hipertensi di Desa Hulu Kecamatan Pancur Batu Tahun 2016. Jurnal Kesehatan Vol. 11(1).

Tjay, Tan Hoan dan Kirana Rahardja, 2007, Obat-Obat Penting Khasiat, Penggunaan dan Efek-Efek Sampingnya, Edisi Keenam, 262, 269-271, PT. Elex Media Komputindo, Jakarta

Tiwari, S., Sirohi B., Shukla A., Bigoniya, P. 2012. Phytochemical Screening And Diuretic Activity of Allium Sativum Steroidal And Triterpenoid Saponin
Fraction. Internasional Journal of Pharmaceutical Sciences and Research Vol. 3(9) : 3354-3361

Wardani dan Adrianta. 2016. Efektivitas Ekstrak Etanol Daun Bayam Merah (Amaranthus Tricolor) Sebagai Diuretik Pada Tikus Putih Jantan Galur Wistar (Rattus Novergicus) : Journal Medicamento Vol.2(2)

Whitten, K.W.; Davis, R.E.; Peck, M.L.; Stanley, G.2009.General Chemistry, Thompson Brooks/Cole, USA

Wright. C. I., Van-Buren. L., Kroner. C. I., Koning. M. M. G., 2007. Herbal medicines as diuretics: A review of the scientific evidence, Journal of Ethnopharmacology 114

(c) (1) () 